\title{
CARGA ADMISSÍVEL DE ESTACAS HÉLICE CONTÍNUA MONITORADA: ANÁLISE COMPARATIVA ENTRE PROVA DE CARGA ESTÁTICA E MÉTODOS SEMIEMPÍRICOS
}

\author{
Karina Fernandes \\ Lucas Fontes Lemos \\ Lucas Motta Santos \\ Victor Pereira Barrot \\ Vitor Fonte Peixoto \\ Kamila Rodrigues Cassares Seko \\ Universidade Presbiteriana Mackenzie (UPM)
}

\begin{abstract}
RESUMO
Este trabalho objetiva estudar metodologias de cálculo da carga admissível de estacas com base nos resultados de uma prova de carga estática prevista na NBR 12131:2006. Sabe-se que, na fase de projeto, a carga admissível da estaca é encontrada mediante o emprego de métodos semiempíricos de previsão de capacidade de carga. Como garantia de que a estaca cumpra devidamente a sua funçáo e como comprovação do fator de segurança previsto pela ABNT (2019), pode-se realizar ensaios em campo, como a própria prova de carga estática. Tal ensaio pode levar a estaca à ruptura, tendo a sua carga admissível determinada de forma direta. Caso contrário, métodos de extrapolação da curva carga vs recalque encontrada no ensaio são utilizados para a determinação desse valor. Com esse pressuposto, este trabalho propóe uma análise comparativa entre carga admissível admitida em projeto para estaca hélice contínua
\end{abstract}


monitorada e as cargas encontradas pela aplicação dos métodos semiempíricos propostos por Chin-Kondner, em 1970, Método convencional (NBR 6122:2019), Van der Veen, em 1953, e Método da Rigidez nos resultados de prova de carga estática com carregamento misto. Após a análise dos resultados, constatou-se a proximidade entre as cargas admissíveis determinadas por meio dos métodos Van der Veen e o convencional em relaçáo ao obtido pelo Método de capacidade de carga proposto por Décourt e Quaresma, em 1996.

Palavras-chave: Carga admissível de estaca hélice contínua monitorada. Prova de carga estática. Métodos semiempíricos para extrapolação da curva carga $v s$ recalque.

\section{INTRODUÇÃO}

A estabilidade e segurança de uma edificação sempre serão prioridades na construção civil. Sabe-se que projetos de Engenharia Civil devem atender aos três requisitos técnicos: estado limite último (ELU), estado limite de serviço (ELS) e durabilidade. No caso das fundaçóes profundas, a capacidade de carga das estacas é baseada nas informaçóes obtidas durante a investigação do subsolo realizada previamente. Pode ser obrigatória a realização de ensaios na fundação executada para verificação do seu desempenho. Os ensaios podem ser: prova de carga estática ou ensaio de carregamento dinâmico. Entre as normas técnicas brasileiras regidas pela Associação Brasileira de Normas Técnicas (ABNT), neste trabalho, foram dadas enfoque nas NBR 6122:2019 e 12131:2006 - a adoção dessa versão é devido ao ano de execução da obra. A ABNT (2019) estabelece os cenários de obrigatoriedade da execução da prova de carga estática e quantidade mínima. Tem-se como resultado dessa prova de carga, geralmente, uma série de dados de cargas e recalques obtidos durante a sua realização. Essa precisará ser interpretada, buscando-se determinar a carga admissível ou a carga de ruptura da estaca, comprovando o desempenho previsto em projeto.

A prova de carga estática nem sempre é conduzida até a ruptura da interação solo-estaca, o que inviabiliza a leitura direta ou imediata da carga de ruptura da estaca na curva carga versus recalque, fazendo surgir a necessidade de aplicação de métodos de extrapolação para determinar essa capacidade de carga. Há métodos de extrapolação disponíveis tanto na literatura nacional quanto na internacional.

Um número pequeno de artigos foi publicado a respeito da interpretação da prova de carga estática em estacas hélice no Brasil. Branco e Alves (2019) assumiram que a 
aplicação do Método de Van der Veen seria suficiente para a determinação da capacidade de carga da estaca. Segundo Décourt e Niyama (1994), esse método é aplicável apenas quando a prova de carga atinge ao menos dois terços da carga de ruptura. Entretanto, a constatação dessa proporção não pode ser atingida sem a ruptura da interação solo-estaca durante a realização da prova de carga estática.

Este artigo diferencia-se do publicado por Branco e Alves em 2019 por aplicar três metodologias para extrapolaçáo da curva carga vs recalque, a saber: Chin-Kondner, em 1970, Van der Veen, em 1953, e Método da Rigidez, proposto por Décourt, em 1999. Deseja-se, com este artigo, contribuir para o aumento de publicaçóes a esse respeito e a compreensão do assunto.

O trabalho analisou o impacto de alguns métodos de extrapolação da curva carga vs recalque de uma prova de carga estática executada em uma estaca Hélice Contínua Monitorada. Os objetivos deste artigo são a interpretação e a análise da curva carga vs recalque obtida com a realização do estudo de caso de uma obra, empregando métodos semiempíricos para a determinação da carga de ruptura e admissível de projeto, e o confronto desta com as cargas de ruptura obtidas pelos métodos de extrapolação que compóem os objetivos.

\section{REVISÁO DA LITERATURA}

As fundaçóes são elementos estruturais que têm por finalidade transmitir os esforços provenientes da estrutura de uma edificação a uma camada resistente do solo. "Há diferentes formas de agrupar os vários tipos de fundação. Uma delas leva em conta a profundidade da ponta, o que dá origem a dois grandes grupos: fundaçóes superficiais ou rasas e as fundaçóes profundas" (CINTRA; AOKI; ALBIERO, 2011, p. 5).

As fundaçóes profundas são elementos em que a carga é transmitida ao terreno apenas pela base/ponta, apenas por suas superfícies laterais ou por ambas, e sua profundidade de assentamento é oito vezes a menor dimensão da fundação ou, no mínimo, três metros. Estão inclusos nessa classe as estacas e os tubulóes. Essas fundaçóes são normalmente utilizadas quando o solo mais próximo à superfície não apresenta capacidade de suporte ou estão sujeitos a processos erosivos. Como o estudo de caso se trata da análise e interpretação de resultados provenientes de um ensaio de carga estática em estaca Hélice Contínua Monitorada, o trabalho aprofundou-se apenas nesse tipo de fundação. 
Velloso e Lopes (2011) classificaram as estacas em três grupos amplos: as de deslocamento, como as pré-fabricadas de madeira, o concreto e as estacas tipo Franki; as que não causam deslocamento algum, como as estacas-raiz; e as de substituição, como as estacas tipo Strauss e as estacas hélice contínua. Essa, no entanto, não é a única forma de classificação. Campos (2015) divide as estacas em dois outros grupos: pré-moldadas e moldadas in loco. Entre as pré-moldadas podem ser citadas as de madeira, concreto e metálicas, seguidas das moldadas in loco, com diferentes métodos executivos. Incluem-se nesta última divisão as brocas, Strauss, Franki, Raiz, escavadas com lama e as estacas hélice contínua monitorada.

As estacas são elementos estruturais que transmitem as cargas da edificação para o solo de três formas: por atrito lateral entre a superfície da estaca e o solo, apenas pela resistência de ponta da estaca ou por uma combinação entre as resistências por atrito lateral e de ponta. $\mathrm{O}$ comprimento útil da estaca dá-se pela diferença entre a cota de arrasamento e cota de ponta, levando em consideraçáo que a cota de arrasamento e de fundo do bloco não são coincidentes.

\subsection{Estaca Hélice Contínua Monitorada - metodologia executiva}

Construtoras estão, cada vez mais, executando a estaca tipo Hélice Contínua Monitorada. Essa preferência ocorre devido a fatores como a produtividade, a não restrição quanto ao tipo de solo e a redução de ruídos devido ao método executivo.

A perfuração do solo ocorre através de um trado helicoidal acoplado a um equipamento sobre esteiras. Após a montagem do trado na máquina e a verificação do prumo, inicia-se a perfuração. É fundamental que o início da perfuração ocorra apenas quando o volume de concreto necessário para executar a estaca já esteja disponível na obra. Os diâmetros do trado podem variar de 30 a 100 centímetros e os comprimentos de 15 até 30 metros (VELLOSO; LOPES, 2011). Ressalta-se que essas características dependem da tecnologia disponível no mercado local.

Após atingir a cota de apoio, sem a retirada prévia do trado, inicia-se a concretagem da estaca, que ocorre simultaneamente à retirada do trado, mantendo uma velocidade adequada para que não haja reduçóes do diâmetro previsto em projeto decorrente de uma instabilidade do solo. Somente após a concretagem da estaca até a cota do terreno, a limpeza do local com a remoção do concreto excedente e do solo fruto da escavação, que é colocada a armação. Essa, por sua vez, é inserida no concreto fresco considerando cota e posicionamento previstos no projeto de fundaçóes. A Figura 1 ilustra as etapas executivas descritas. 


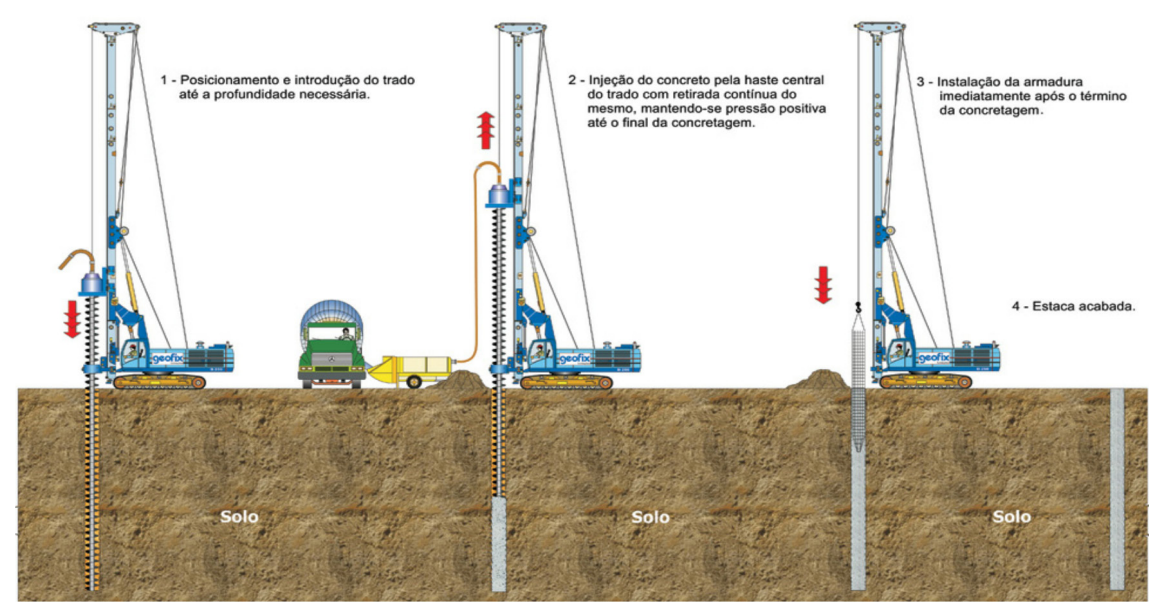

Figura 1 Processo executivo de uma estaca do tipo hélice contínua.

Fonte: Estaca hélice, de Geofix Fundações (2020).

Vale ressaltar que um equipamento acoplado à cabine da máquina monitora dados como a profundidade de escavação, velocidade de rotaçáo, torque, inclinação da torre e pressão do concreto na linha próximo ao topo da torre, que são fornecidos na forma de relatório pela empresa executora após o término dos serviços.

Algumas desvantagens que podem ser destacadas são o porte avantajado do equipamento, a inevitabilidade de áreas planas para a locomoção com segurança do equipamento e a produçáo mínima com o intuito de compensar o custo da mobilizaçáo.

\subsection{Método Semiempírico Décourt-Quaresma de 1996 para determinaçáo da capacidade de carga}

Após definir o tipo de estaca a ser executada na obra, é necessário que o calculista especifique, em projeto, o(s) diâmetro(s) das estacas e seu(s) respectivo(s) comprimento(s), para atender adequadamente à dissipação dos esforços ao solo. Para isso, são utilizados métodos semiempíricos que objetivam indicar o parâmetro desejado analisando as características da estaca. Os três métodos mais utilizados no Brasil para a estaca hélice contínua monitorada são o Aoki-Velloso, de 1975 com aprimoramentos, o Décourt-Quaresma, de 1996, e o Teixeira, de 1996. Neste trabalho foi empregado o Método Décourt-Quaresma de 1996, que será descrito a seguir.

Esse método caracteriza-se pela determinação da capacidade de carga da estaca utilizando somente os valores de índice de resistência à penetração obtidos durante os 
ensaios de penetração padrão (SPT - Standard Penetration Test). O conceito do método tem, por princípio, o mesmo empregado no método de Aoki-Velloso, com o qual se determina a capacidade de carga de uma estaca por meio das suas cargas resistências de ponta $\left(R_{P}\right)$ e por atrito lateral $\left(R_{L}\right)$. As expressóes que Luciano Décourt e Arthur Quaresma apresentaram em 1978, inicialmente, são:

$$
R_{L}=r_{L} \cdot U \cdot L \mathrm{e}
$$

$$
R_{P}=r_{P} \cdot A_{P}
$$

Em que:

$U$ é o perímetro da seção transversal da estaca;

$L$ é o seu comprimento;

$A_{P}$ é a área da seção transversal da ponta da estaca.

A tensão resistente por atrito lateral $\left(r_{L}\right)$, encontrada na unidade de $\mathrm{kPa}$ com o emprego da Equação (3), apresentada a seguir, é em função do valor médio do índice de resistência à penetração do SPT ao longo do fuste $\left(N_{L}\right)$.

$$
r_{L}=10\left(\frac{N_{L}}{3}+1\right)
$$

Já a tensão resistente de ponta $\left(r_{P}\right)$, na unidade de $\mathrm{kPa}$, pode ser obtida pela equação:

$$
r_{P}=C \cdot N_{P}
$$

Em que o valor médio do índice de resistência à penetração na ponta da estaca $\left(N_{P}\right)$ é obtido por meio do cálculo com valor de índice de resistência à penetração adquirido na ponta da estaca, o valor imediatamente anterior à ponta e o imediatamente posterior à ponta. Deve-se empregar um coeficiente característico do solo $\mathrm{C}$ a ser adotado por meio da Tabela 1 a seguir. 
TABELA 1

Coeficiente característico do solo (C)

\begin{tabular}{cc} 
Solo & C $(\mathbf{k P a})$ \\
\hline Argila & 120 \\
\hline Silte argiloso & 200 \\
Silte arenoso & 250 \\
Areia & 400 \\
\hline
\end{tabular}

Fonte: Cintra e Aoki (2010, p. 27).

Segundo Décourt (1996 apud CINTRA; AOKI, 2010), introduziram-se fatores a e $\beta$ (apresentados nas tabelas 2 e 3 a seguir) nas parcelas de resistência de ponta e lateral, respectivamente, resultando na seguinte expressão para o cálculo da capacidade de carga sem fator de segurança em:

$$
R=\alpha C N_{P} A_{P}+\beta 10\left(\frac{N_{L}}{3}+1\right) U L
$$

\section{TABELA 2}

Valores do fator $\alpha$ em função do tipo de estaca e do tipo de solo

\begin{tabular}{lccccc} 
& \multicolumn{5}{c}{ Tipo de estaca } \\
\cline { 2 - 6 } Tipo de solo & $\begin{array}{c}\text { Escavada em } \\
\text { geral }\end{array}$ & $\begin{array}{c}\text { Escavada } \\
\text { (bentonita) }\end{array}$ & $\begin{array}{c}\text { Hélice } \\
\text { contínua }\end{array}$ & Raiz & $\begin{array}{c}\text { Injetada sob altas } \\
\text { pressões }\end{array}$ \\
\hline Argilas & 0,85 & 0,85 & 0,3 & 0,85 & 1,0 \\
Solos intermediários & 0,6 & 0,6 & 0,3 & 0,6 & 1,0 \\
Areias & 0,5 & 0,5 & 0,3 & 0,5 & 1,0 \\
\hline
\end{tabular}

Fonte: Cintra e Aoki (2010, p. 28). 


\section{TABELA 3}

Valores do fator $\beta$ em função do tipo de estaca e do tipo de solo

\begin{tabular}{lccccc} 
& \multicolumn{5}{c}{ Tipo de estaca } \\
\cline { 2 - 6 } \multicolumn{1}{c}{ Tipo de solo } & $\begin{array}{c}\text { Escavada em } \\
\text { geral }\end{array}$ & $\begin{array}{c}\text { Escavada } \\
\text { (bentonita) }\end{array}$ & $\begin{array}{c}\text { Hélice } \\
\text { contínua }\end{array}$ & Raiz & $\begin{array}{c}\text { Injetada sob altas } \\
\text { pressões }\end{array}$ \\
\hline Argilas & 0,8 & 0,9 & 1,0 & 1,5 & 3,0 \\
\hline Solos intermediários & 0,65 & 0,75 & 1,0 & 1,5 & 3,0 \\
\hline Areias & 0,5 & 0,6 & 1,0 & 1,5 & 3,0 \\
\hline
\end{tabular}

Fonte: Cintra e Aoki (2010, p. 28).

Ressalta-se que para estacas tipo Franki e pré-fabricadas, os valores dos coeficientes a e $\beta$ sáo iguais a 1,0. O método em questáo apresenta fatores de segurança intermediários, proporcionando uma expressão para cálculo da carga admissível dada por:

$$
P_{a d m}=\frac{R_{P}}{4}+\frac{R_{L}}{1,3}
$$

No caso de estacas hélice contínua monitorada, se o executor garantir que o procedimento foi executado de maneira correta seguindo as especificaçốes da ABNT (2019), tem-se a carga resistente de ponta limitada ao valor da carga resistente por atrito lateral $\left(R p \leq R_{L}\right)$ e as seguintes equaçóes para determinar a carga admissível da estaca:

$$
P_{a d m} \leq\left\{\begin{array}{c}
\frac{R}{2}=\frac{R p+R_{L}}{2} \\
\frac{R_{P}}{4}+\frac{R_{L}}{1,3}
\end{array}\right.
$$

Caso contrário, o cenário altera-se para a consideração de uma carga resistente de ponta nula e a carga admissível passa a ser obtida por meio das seguintes equaçóes:

$$
P_{a d m} \leq\left\{\begin{array}{c}
\frac{R}{2}=\frac{R_{L}}{2} \\
\frac{R_{L}}{1,3}
\end{array}\right.
$$




\subsection{Prova de carga estática}

Como mencionado anteriormente, no projeto de fundaçôes de qualquer obra, utilizam-se métodos semiempíricos para a obtenção da capacidade de carga, com intuito de determinar o valor da carga admissível e o comprimento de uma estaca. Por meio desse procedimento, adota-se um valor teórico de resistência $(\mathrm{R})$ e de solicitação (S) da qual a estaca será submetida. Conhecidos os valores médios de resistência (Rmed) e solicitação (Smed) de um conjunto n de estacas, pode-se definir o fator de segurança global (Fs), que se dará pela fórmula a seguir:

$$
F s=\frac{\text { Rmed }}{\text { Smed }}
$$

Os valores teóricos diferem dos valores reais, que só serão descobertos após a execução da estaca. Segundo Cintra, Aoki, Tsuha e Giacheti (2013, p. 58), “ignorar os valores reais de capacidade de carga acarreta uma consequência grave: o desconhecimento do fator de segurança real da fundação". Para conhecimento dos valores reais, executam-se ensaios de campo nas estacas previamente executadas. Os dois existentes e previstos na NBR 6122 (ABNT, 2019) sáo o ensaio de carregamento dinâmico e a prova de carga estática. O ensaio de carregamento dinâmico consiste em deslocamentos verticais realizados por golpes de bate-estacas e captados por sensores instalados na estaca. Esses deslocamentos são analisados e transformados em um relatório emitido pela empresa contratada para a realização do ensaio. A prova de carga estática é, basicamente, aplicar esforços estáticos à estaca e registrar os deslocamentos correspondentes. Os esforços aplicados podem ser axiais, de tração ou de compressão, ou transversais (ABNT, 2006).

O elemento de fundação é solicitado por um ou mais macacos hidráulicos, que acrescentam gradativamente a carga mediante estágios de carregamentos sucessivos ao sistema de reação estável criado.

O sistema de reação deve ser projetado, montado e utilizado de forma que a carga aplicada atue na direção desejada, sem produzir choques ou vibraçôes. Podem ser no formato de plataforma carregada ou estruturas fixadas no terreno por meio de elementos tracionados (ABNT, 2006, p. 1)

A carga suportada deve ser maior que a carga admissível da fundação, valor previsto em projeto. Adota-se, geralmente, o dobro da carga de solicitação. Portanto, um fator de segurança igual a 2,0. 
O manômetro é o responsável por monitorar e mostrar a carga atuante durante o estágio de carregamento, e os deflectômetros instalados no bloco de coroamento realizam a leitura do deslocamento efetivo da estaca. Vale ressaltar que os deflectômetros têm como referência as vigas instaladas e apoiadas em regióes não afetadas pela prova de carga estática.

O tipo de carregamento utilizado no ensaio é definido pelo calculista do projeto de fundaçóes. As possibilidades de carregamento previstos pela NBR 12131 (ABNT, 2006) e descritos a seguir são: lento, rápido, misto e cíclico.

No carregamento lento, sua execução é dividida em estágios iguais e sucessivos. Em cada estágio, a carga deve ser mantida até a estabilização dos deslocamentos e por 30 minutos, no mínimo. Os deslocamentos devem ser lidos imediatamente após a aplicação da carga correspondente, seguindo-se leituras após dois, quatro, oito e 15 minutos, uma, duas, três e quatro horas, e assim sucessivamente. As leituras dos deslocamentos são realizadas com o auxílio de deflectômetros, e a estabilização ocorre quando a diferença entre duas leituras consecutivas corresponde a, no máximo, 5\% do deslocamento no mesmo estágio. A carga aplicada em cada estágio de carregamento não deve ser superior a $20 \%$ da carga de trabalho prevista para a estaca ensaiada. Finalizada a etapa de carregamento, a carga máxima deve ser mantida por, no mínimo, 12 horas entre a estabilização dos recalques e o início do descarregamento, que deve ser realizado em, pelo menos, quatro estágios. Cada estágio é mantido ao menos por 15 minutos, seguindo os critérios anteriormente descritos. Após o descarregamento total, as leituras dos deslocamentos devem continuar até a sua estabilização (ABNT, 2006).

Já no carregamento rápido, deve-se manter, em cada estágio, a carga constante por 10 minutos, independentemente da estabilização dos deslocamentos. A carga aplicada em cada estágio não deve ser superior a $10 \%$ da carga de trabalho prevista. Atingida a carga máxima, são realizados, para esse estágio específico, cinco leituras: de 10, 30, 60, 90 e 120 minutos. A seguir, deve ocorrer o descarregamento em cinco estágios ou mais, de 10 minutos cada, efetuando-se as respectivas leituras dos deslocamentos. Finalizado o descarregamento total, decorridos 10 minutos, são realizadas mais duas leituras adicionais, aos 30 e 60 minutos (ABNT, 2006).

Ainda segundo a ABNT (2006), a NBR 12131 permite o emprego do carregamento misto, em que se deve aplicar o carregamento lento até atingir 1,2 vezes a carga de trabalho prevista. Em seguida, adota-se a metodologia prevista para o carregamento rápido.

E, por último, existe o tipo de carregamento denominado cíclico, que é composto por ciclos de carga-descarga com incrementos iguais e sucessivos. $\mathrm{O}$ carregamento cíclico possui dois tipos (lento e rápido), nos quais os critérios de incremento máximo e de estabilização dos deslocamentos são os mesmos evidenciados neste artigo para cada tipo de carregamento. A diferença encontra-se no descarregamento: no cíclico 
lento, o descarregamento ocorre de uma só vez e a carga nula no topo é mantida até a estabilização dos deslocamentos; no cíclico rápido, a carga nula é mantida por 10 minutos, com a leitura dos deslocamentos, e, decorrido esse tempo, realizam-se mais duas leituras adicionais, de 30 e 60 minutos.

Assim como no ensaio de carregamento dinâmico, os dados obtidos são enviados à equipe técnica da empresa responsável pelo ensaio, que emite um relatório contendo a metodologia adotada, a descrição dos resultados e a ilustração da curva carga $v$ recalque do procedimento na estaca.

\subsection{Métodos de extrapolaçáo}

"Quando uma prova de carga não é levada até a ruptura ou a um nível de recalque que caracterize ruptura, pode-se realizar uma extrapolação da curva carga-recalque, com objetivo de estipular a carga de ruptura da estaca" (MONTEIRO; ARAÚJO; AGUIAR, 2017, p. 8). A seguir, serão apresentados os métodos empregados no estudo de caso deste trabalho.

\subsubsection{Método proposto por Chin-Kondner em 1970}

O método proposto por Chin-Kondner possibilita a extrapolação da carga de ruptura em ambos os ensaios estáticos de prova de carga, seja do tipo carregamento lento, seja do tipo rápido. $\mathrm{O}$ método divide cada recalque pela respectiva carga aplicada e os coloca no eixo das ordenadas. No eixo das abscissas, são colocados os recalques obtidos durante a prova de carga estática. Na Figura 2, é mostrado um gráfico típico da aplicação do método, em que se observa esta curva sendo indicada por cruzetas na cor vermelha. 


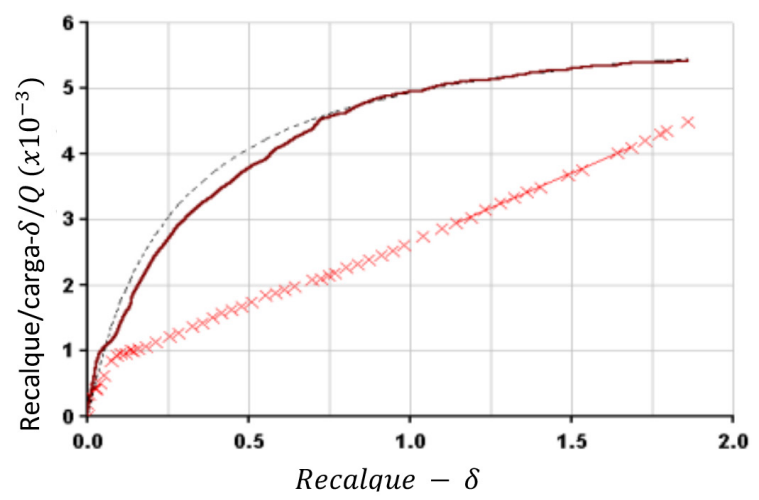

Figura 2 Gráfico-padrão da aplicação do Método de Chin-Kondner.

Fonte: Adaptado de Fellenius (2020, p. 8-4).

A carga limite última, obtida a partir da curva em cruzetas vermelhas, é dada de acordo com a equação:

$$
Q_{u}=\frac{1}{C_{1}}
$$

Em que:

$Q_{u}$ - carga limite última;

$C_{1}-$ inclinação da linha reta.

Já a curva ideal, representada também na Figura 2 (curva tracejada), possui a seguinte equação:

$$
\mathrm{Q}=\frac{\delta}{C_{1} \cdot \delta+C_{2}}
$$

Em que:

Q - carga aplicada;

$C_{1}$ - inclinação da linha reta;

$C_{2}$ - intersecção com eixo $\mathrm{Y}$;

$\delta$ - recalque correspondente à carga aplicada. 
O método Chin-Kondner pode ser aplicado em ambos os ensaios com carregamento rápido ou lento, desde que intervalos de tempos constantes entre incrementos de cargas sejam usados (FELLENIUS, 2020).

\subsubsection{Método convencional (NBR 6122:2019)}

O método baseia-se nos conceitos do método de Davisson, proposto em 1972, no qual se muda a parcela referente ao deslocamento plástico inicial. Essa metodologia é dada pela formulação a seguir:

$$
\rho=\frac{D}{30}+\frac{Q \cdot L}{E \cdot S}
$$

Em que:

$\rho$ - recalque para uma carga aplicada;

D - diâmetro da estaca;

L - comprimento da estaca;

Q - carga aplicada;

E - módulo de Young da estaca;

$S$ - área de sessão transversal da estaca.

A Figura 3 apresenta o método proposto pela norma brasileira - este não foi modificado em suas versóes subsequentes.

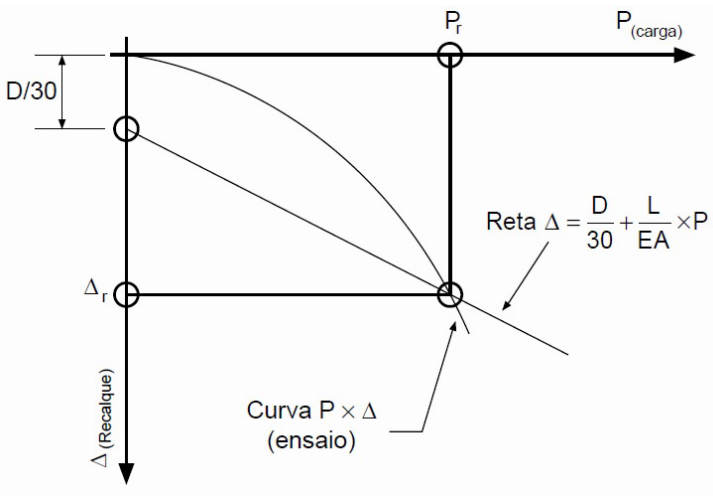

Figura 3 Método gráfico da NBR 6122:2019.

Fonte: ABNT (2019, p. 27). 
De acordo com a ABNT (2019), a NBR 6122 permite a extrapolação da curva para avaliar a carga de ruptura em duas circunstâncias. A primeira é caracterizada pela carga de ruptura da estaca superior à carga máxima que se pretende aplicar; a segunda é definida pela aplicação de carregamentos que conduzem a recalques elevados, mas sem que uma ruptura nítida seja notada. Em estruturas sujeitas a esforços cíclicos, as provas de carga devem ser programadas de modo a ajustar-se à influência desse tipo de carregamento.

\subsubsection{Método proposto por Van der Veen em 1953}

O método consiste no aspecto exponencial da relação entre a carga e o deslocamento no topo, dado pela equação a seguir (FRANÇA, 2011).

$$
\mathrm{Q}=Q_{\text {ult }} \cdot\left(1-e^{-\propto \cdot r}\right)
$$

Em que:

Q - carga aplicada no topo da estaca;

Qult - carga de ruptura;

a - coeficiente que define a forma da curva;

$\mathrm{r}$ - recalque correspondente à carga aplicada.

Com base nos parâmetros anteriores e após algumas transformaçôes, aplicando a propriedade dos logaritmos, tem-se:

$$
\propto . r=-\ln \left(1-\frac{Q}{Q_{u l t}}\right)
$$

Em que os valores resultantes da expressão logarítmica devem ser plotados no eixo da abscissa e os recalques, no eixo da ordenada. A Figura 4 demonstra o método gráfico. A curva que proporcionará a carga de ruptura do ensaio será com maior linearidade entre os pontos finais. Destaca-se que essa é a versão do Método Proposto por Van der Veen, em 1953, adaptado por Aoki, em 1976. 


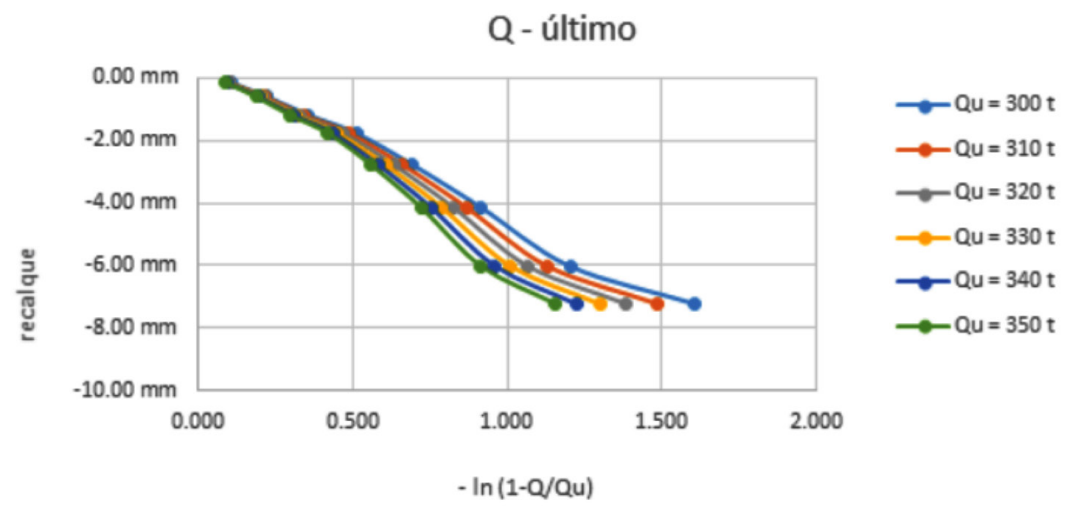

Figura 4 Gráfico correspondente ao método de Van der Veen.

Fonte: Bessa et al. (2016).

O método de Van der Veen é baseado em três hipóteses básicas para apresentar resultados satisfatórios:

1) a forma da curva deve ser do tipo exponencial;

2) o modo de ruptura é do tipo física, correspondendo a recalques teoricamente infinitos;

3) é aplicável somente se o ensaio atingiu ao menos dois terços da carga de ruptura.

Assim, se o ensaio não seguir uma dessas hipóteses, ele pode não apresentar resultados satisfatórios.

\subsubsection{Método proposto por Décourt em 1999}

O método proposto por Décourt é similar ao proposto por Chin-Kondner. Deve-se realizar o quociente entre carga e recalque lidos na prova de carga estática e elaborar um gráfico de Carga vs Carga/Recalque (FELLENIUS, 2020). Realiza-se a regressão linear dos últimos pontos por meio de uma equação que determina a carga de ruptura e a expressão da curva carga $v$ s recalque, conforme apresenta a Figura 5.

$$
\mathrm{Q}_{u}=\frac{C_{2}}{C_{1}} e
$$




$$
\mathrm{Q}=\frac{C_{2} \delta}{1-C_{1} \delta}
$$

Em que:

$Q$ - carga na estaca;

$Q_{u}$ - carga de ruptura;

$\delta$ - recalque;

$C_{1}$ - coeficiente angular da reta obtida;

$C_{2}-$ valor de carga correspondente ao quociente entre carga e recalque nulo.
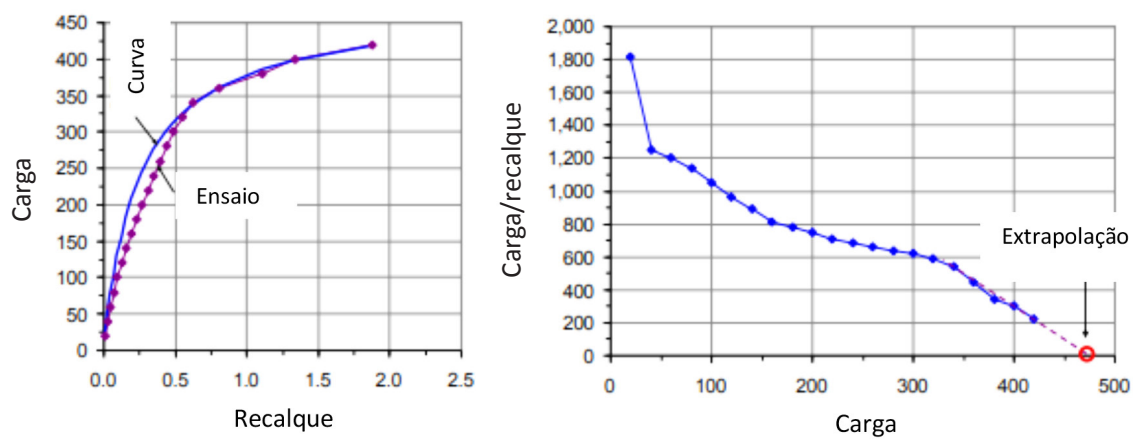

Figura 5 Método de extrapolação Décourt.

\section{METODOLOGIA}

Foi realizada uma pesquisa exploratória sobre os métodos semiempíricos de previsão de capacidade de carga, com foco no Método Décourt-Quaresma de 1996; na necessidade de estudo da carga de ruptura da estaca por meio da prova de carga estática (NBR 12131), assim como sua metodologia executiva; e nos métodos de interpretação da curva carga $v$ s recalque resultante desse ensaio.

Uma obra foi escolhida para estudo de caso, a qual apresenta relatório de sondagem a percussão com SPT, projeto de fundaçóes em estaca hélice contínua e relatório da prova de carga estática executada em uma estaca de diâmetro 50 centímetros. 
Destaca-se que a prova de carga estática foi executada com aplicação de carregamento misto. Com o objetivo de interpretar a curva carga vs recalque, a análise dos dados coletados será via extrapolação da curva carga vs recalque, utilizando os métodos de Chin-Kondner, Van der Veen, norma brasileira (NBR 6122:2019) e método de Décourt.

A previsão da capacidade de carga da estaca foi executada empregando o método semiempírico Décourt-Quaresma. Esses valores estimados foram confrontados aos determinados pela interpretação da curva. Os resultados, por sua vez, foram apresentados em forma de tabelas e a análise consiste também no uso de parâmetros estatísticos.

\section{ESTUDO DE CASO}

A estaca ensaiada faz parte de uma edificação institucional de ensino que possui quatro pavimentos (térreo, $1^{\circ}, 2^{\circ}$ e $3^{\circ}$ pavimentos), com quase 20 metros de altura. $\mathrm{A}$ estrutura é pré-fabricada, os pilares, as vigas e os painéis são de concreto armado, e as lajes são de concreto protendido. O empreendimento está localizado na zona Sul de São Paulo, mais precisamente na Rua Subaé, 58, Jardim Umarizal. Para conhecer as características do solo, foi realizada a sondagem do terreno. No relatório, emitido em forma de perfis geológico-geotécnicos, evidenciaram-se os perfis de solo em cinco pontos de referência distintos, totalizando 114,10 metros de perfuração.

Nesse processo, demonstrado pelo relatório 332.81.806 da BRSonda, uma sonda de diâmetro $\phi 2$ 1 12 ” foi utilizada. $\mathrm{O}$ índice de resistência à penetração foi obtido através do ensaio SPT, realizado de metro em metro, com o auxílio de um amostrador Terzaghi.

Pela locação em que a "estaca teste" se encontra no terreno, conforme apresenta a Figura 6, a sondagem de referência escolhida foi a SP-02: 


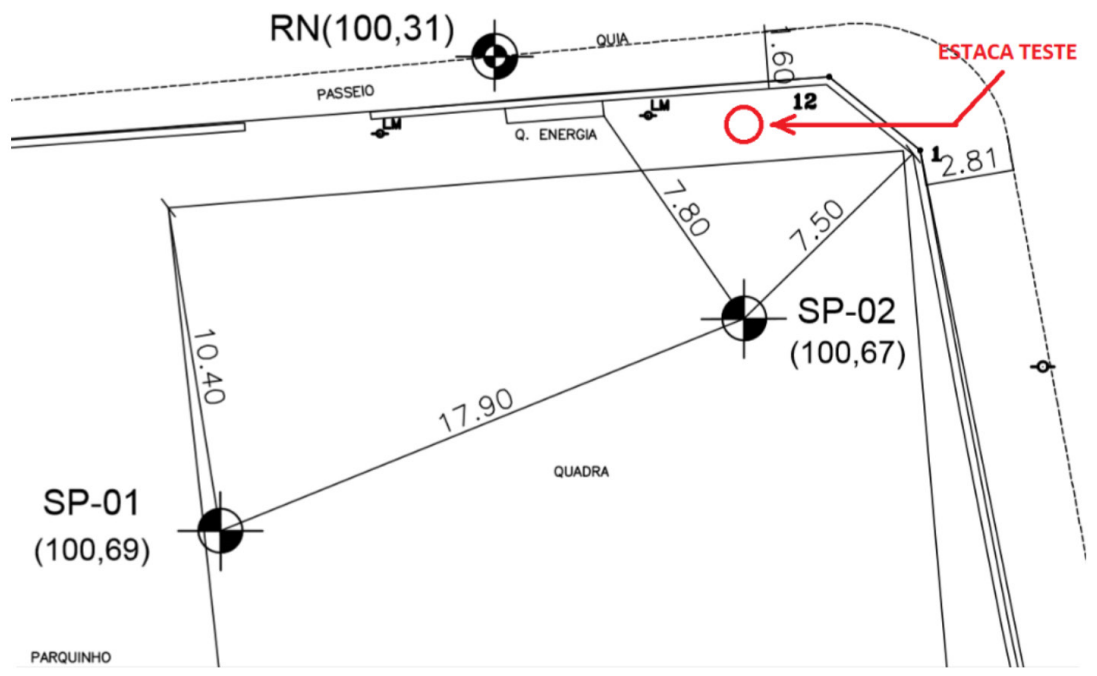

Figura 6 Locação da estaca teste.

Fonte: BRSonda (2018).

Consultando o relatório de sondagem e analisando o SP2 em relação ao comprimento da estaca, observa-se um silte argiloso pouco arenoso variegado cinza-claro muito mole, com $N_{S P T}$ de, em média, dois golpes, numa espessura de aproximadamente 94 centímetros. $\mathrm{Na}$ camada seguinte, evidenciou-se um silte argiloso pouco arenoso variegado vermelho-amarelado mole e $N_{S P T}$ de quatro golpes numa extensão de 1,28 metros. Entre quatro e 16 metros, aproximadamente, tem-se um silte argiloarenoso variegado com consistência de média a dura e $N_{S P T}$ médio de 15 golpes. De 16 metros até a ponta da estaca estudada, percebe-se um silte arenoargiloso cinza, variando sua compacidade de medianamente compacta a muito compacta com $N_{S P T}$ médio de 33 golpes.

O projeto previa a execução de 126 estacas, incluindo a estaca teste, distribuídas ao longo do terreno, com comprimentos variando de 22 a 25 metros. Foram especificados em projeto diâmetros de 25, 40, 50 e 60 centímetros para cargas admissíveis de 140 a $1150 \mathrm{kN}$ das estacas.

A estaca Hélice Contínua Monitorada adotada para o ensaio possui 22 metros de comprimento, com diâmetro de 50 centímetros e seção transversal circular. A carga admissível de projeto para a estaca foi de $1.000 \mathrm{kN}$ e a distância mínima entre o ponto de sondagem SP-02 e a estaca teste foi respeitada, uma vez que está dentro do especificado na NBR 12131 (uma área definida por um círculo de diâmetro igual a dez vezes o diâmetro da estaca em questão ou, no máximo, cinco metros). 
A prova de carga estática na estaca teste Hélice Contínua Monitorada ocorreu no dia 25 de novembro de 2019. O sistema de reação foi composto por três vigas metálicas ancoradas no terreno por seis estacas helicoidais metálicas, conforme as figuras 7 e 8 a seguir.

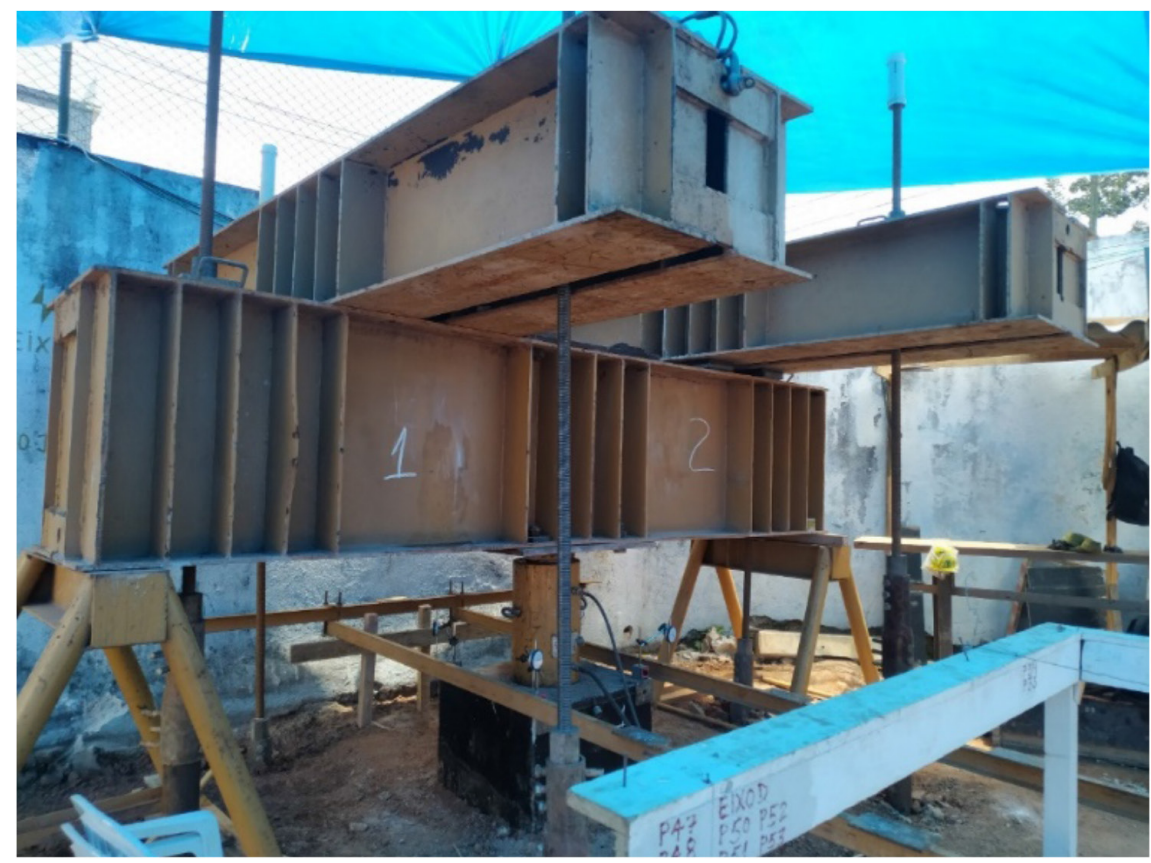

Figura 7 Sistema de reação de uma prova de carga estática.

Fonte: Acervo pessoal dos autores.

O carregamento adotado para a realização da prova de carga estática foi do tipo misto.

A etapa de carregamento lento foi dividida em seis estágios de 30 minutos (os recalques estabilizaram em intervalo de tempo inferior) e com acréscimo de $200 \mathrm{kN}$ cada, isto é, até atingir $1.200 \mathrm{kN}$. Foram realizadas cinco leituras durante cada estágio e a estabilizaçáo dos deslocamentos foi determinada a partir de leituras dos deflectômetros instalados no sistema, sendo admitido o valor no qual a diferença entre duas leituras consecutivas correspondesse a, no máximo, 5\% do deslocamento havido no estágio. 


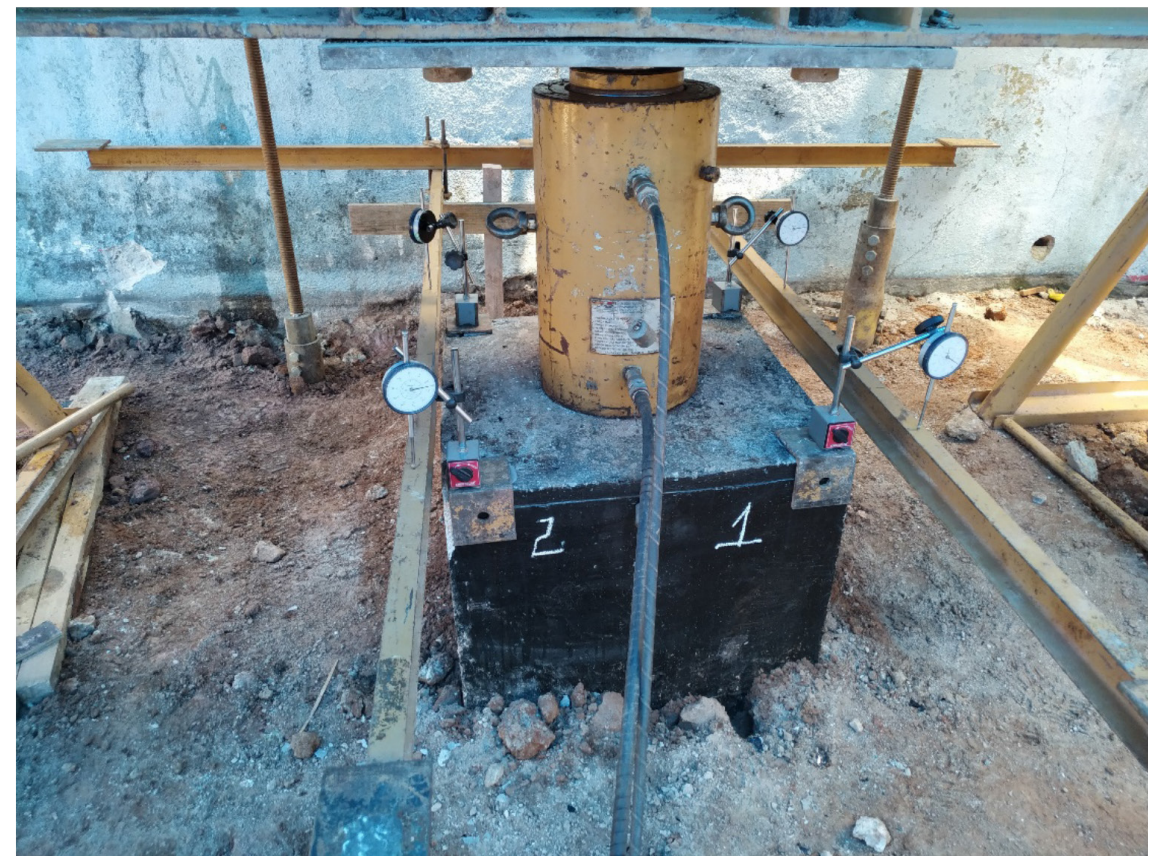

Figura 8 Macaco hidráulico e deflectômetros empregados na prova de carga.

Fonte: Acervo pessoal dos autores.

Após a estabilização do sexto estágio, o carregamento empregado no ensaio passou para o tipo rápido. Essa etapa foi dividida em oito estágios de $100 \mathrm{kN}$ cada. A leitura nos deflectômetros ocorreu logo após a aplicação da carga, 10 minutos depois, independentemente da estabilização dos deslocamentos, até se atingir o valor de $2.000 \mathrm{kN}$ (carga adotada no projeto com fator de segurança igual a 2,0). Ao atingir a carga máxima, foram realizadas leituras na sequência da aplicação da última carga e aos 10, 30, 60, 90 e 120 minutos seguintes; finalizando a etapa de carregamento. O recalque total ocorrido na estaca ao ser submetida à uma carga máxima foi de 7,88 $\mathrm{mm}$.

O descarregamento foi realizado em cinco estágios de $400 \mathrm{kN}$, mantidos por 10 minutos cada. A leitura dos respectivos deslocamentos ocorreu logo após a aplicação da carga e aos 10 minutos. Após o descarregamento total da estaca, foram realizadas leituras aos 30 e 60 minutos seguintes e constatou-se um recalque permanente da estaca de $2,46 \mathrm{~mm}$.

Com as leituras realizadas pelos deflectômetros e analisando o relatório do ensaio, foi obtida a curva carga $v$ s recalque (Figura 9) da estaca ensaiada. 


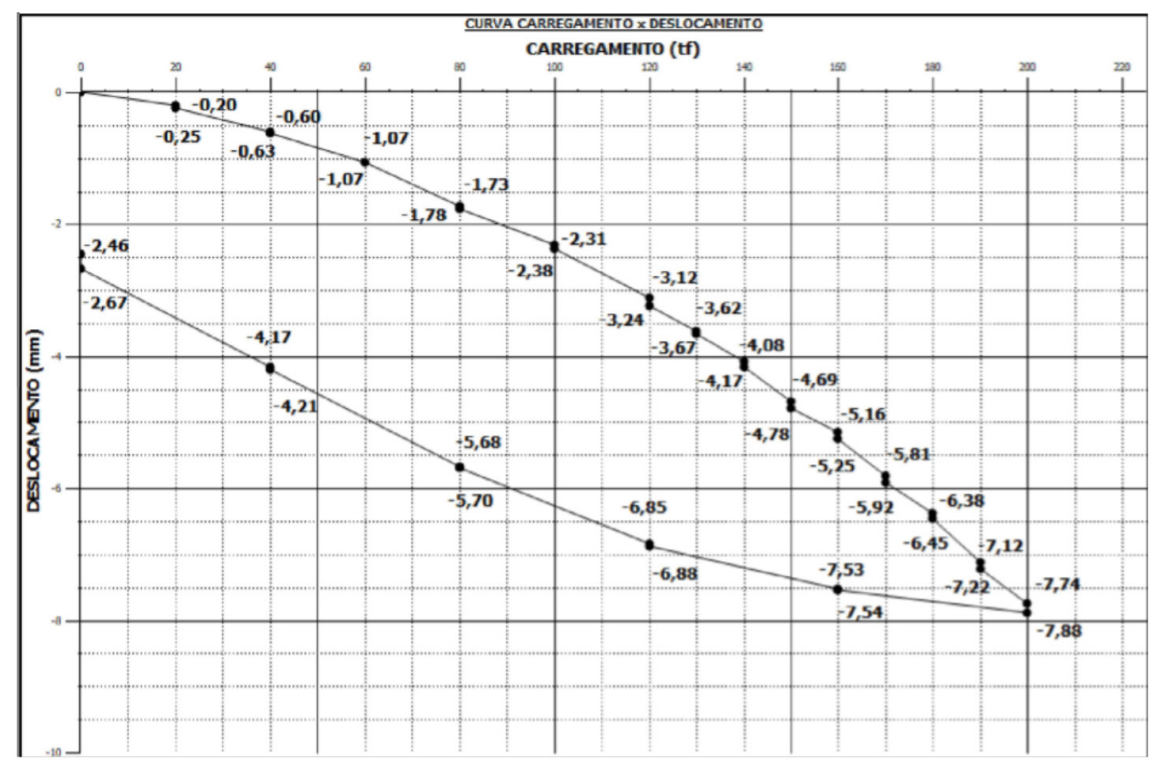

Figura 9 Curva carga versus recalque da estaca ensaiada.

Fonte: Trio Fundações (2019).

Com base na teoria detalhada no item 2.2 (Método Semiempírico Décourt-Quaresma), nas características geométricas da estaca e nas especificaçôes da investigação do solo, obteve-se uma estimativa da carga admissível para essa estaca teste no valor de $1.340 \mathrm{kN}$; foi possível também encontrar a carga de ruptura, somando o valor da carga resistente de ponta e por atrito lateral, no valor de $2.685 \mathrm{kN}$.

Analisou-se a curva carga $v$ recalque decorrente da prova de carga estática e percebeu-se que não houve ruptura. Assim, viu-se a necessidade de aplicar os métodos semiempíricos de extrapolação. Iniciou-se a extrapolação com o emprego do método proposto por Van der Veen, em 1953. Foram adotados valores de carga de ruptura entre 2.500 e $3.000 \mathrm{kN}$. Após a observação das curvas obtidas e apresentadas na Figura 10, chegou-se à conclusão de que a carga de ruptura seria de $2.600 \mathrm{kN}$. Com tal parâmetro, pode-se construir uma previsão de curva carga vs recalque. Observa-se na Figura 11 que a curva prevista apresenta boa aderência em relaçáo aos resultados obtidos na prova de estática, validando a carga de ruptura obtida por meio da aplicação desse método em questão. 


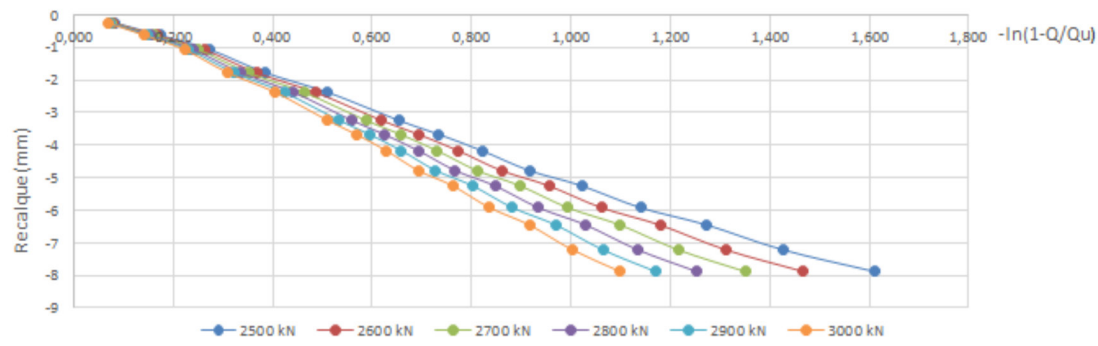

Figura 10 Gráfico para a obtenção da Carga de Ruptura proposto por Van der Veen em 1953.

Fonte: Elaborada pelos autores.

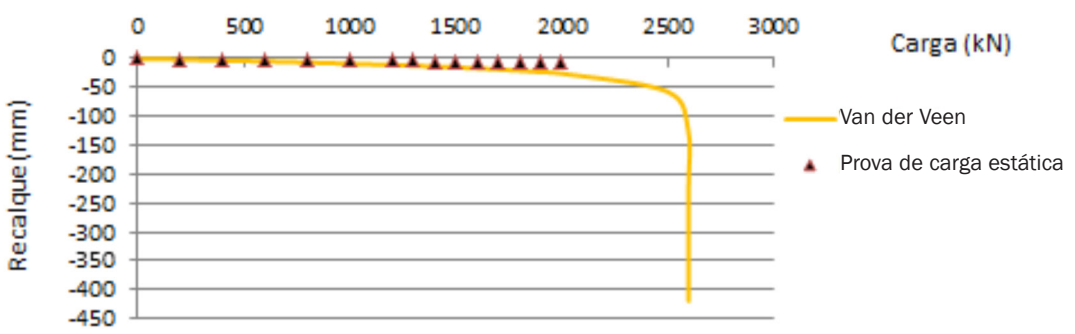

Figura 11 Previsão de curva carga versus recalque por meio do método proposto por Van der Veen em 1953.

\section{Fonte: Elaborada pelos autores}

O segundo método de extrapolação aplicado foi o método proposto por Chin-Kondner, em 1970. Foi elaborado um gráfico de recalque vs recalque/carga como proposto pelos autores (Figura 12). Ao analisar a Figura 12, é possível observar a linearidade dos últimos nove pontos, sendo possível realizar a regressão linear com esses dados e determinar que a carga de ruptura é de $3.333 \mathrm{kN}$. 


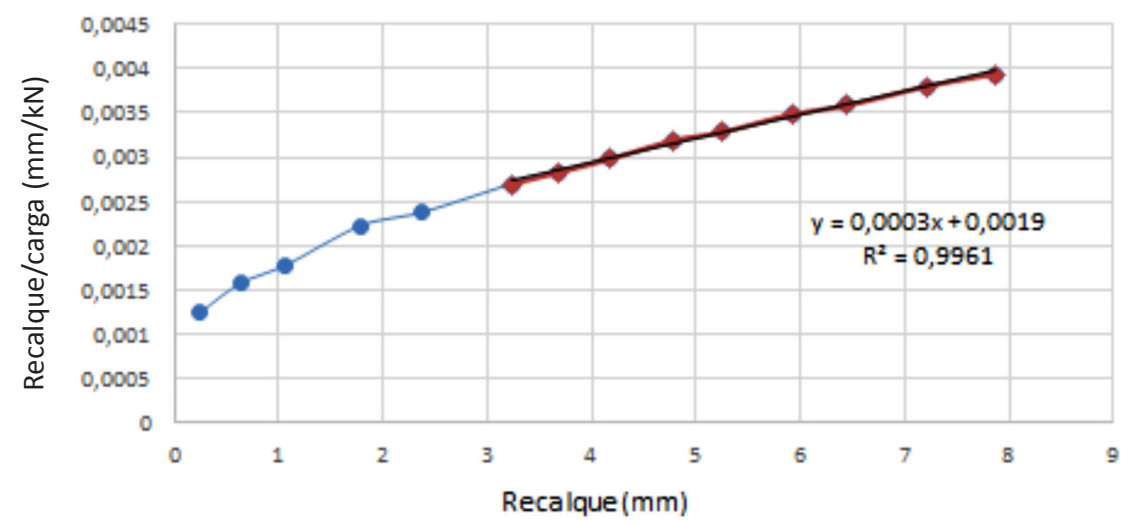

Figura 12 Curva recalque/carga versus recalque método proposto por Chin-Kondner em 1970.

Fonte: Elaborada pelos autores.

Com a definição dos parâmetros do método e o emprego da Equação (11), tem-se a previsão de uma curva carga $v$ recalque extrapolada, apresentada na Figura 13.

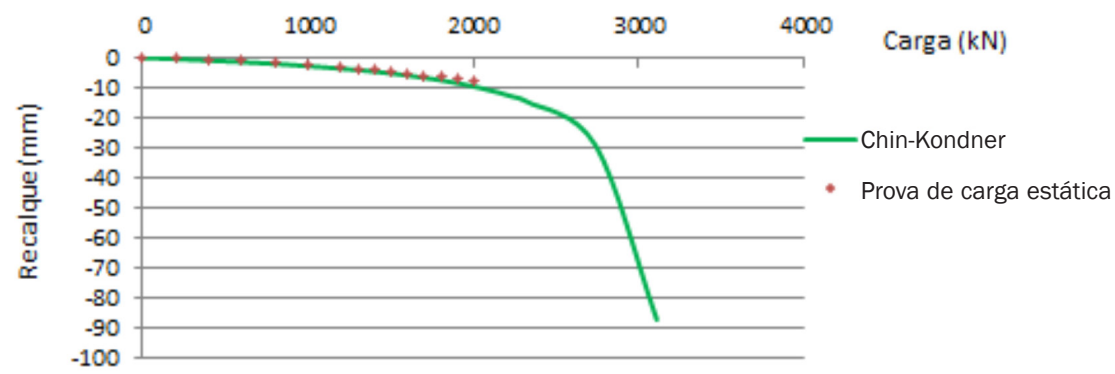

Figura 13 Extrapolação da curva pelo método proposto por Chin-Kondner em 1970.

Fonte: Elaborada pelos autores.

O terceiro método empregado foi o proposto por Décourt, em 1999. A Figura 14 apresenta a curva e os seus parâmetros que permitiram a obtençáo de uma carga de ruptura com magnitude de 3.693 kN. Por meio desse valor e da Equação (16), obteve-se a curva extrapolada de carga $v$ s recalque (Figura 15). Novamente, observa-se a proximidade entre resultados da prova de carga e valores obtidos com o método. 


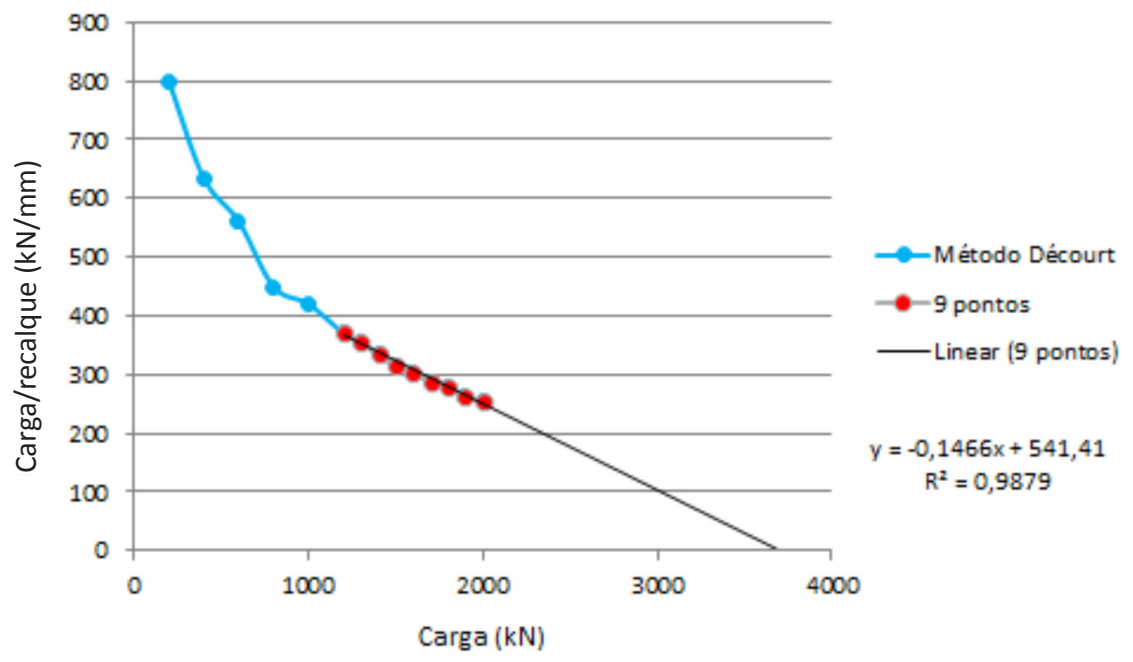

Figura 14 Curva carga versus carga/recalque método proposto por Décourt em 1999.

Fonte: Elaborada pelos autores

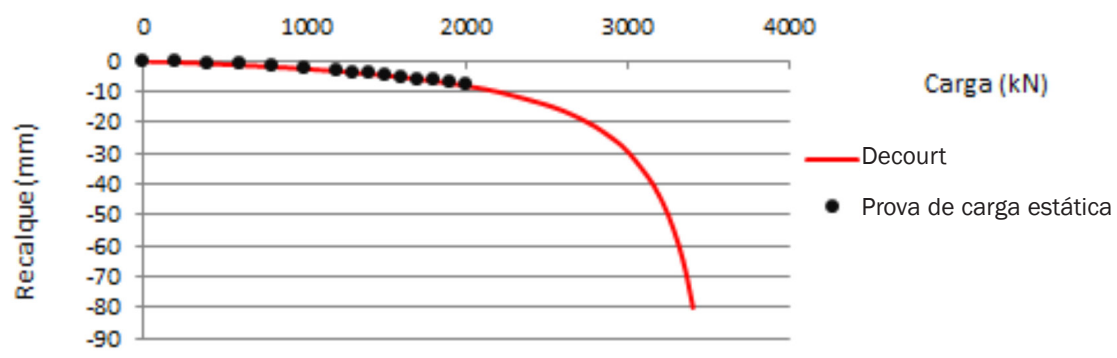

Figura 15 Extrapolação da curva pelo método proposto por Décourt em 1999.

Fonte: Elaborada pelos autores

Por não existir uma curva carga $v$ s recalque com ruptura clara e a constatação de que, ao empregar o Método Convencional da ABNT (2019) da NBR 6122 não houve intersecção entre curva e reta, optou-se por aplicar o método em questão na curva extrapolada com o Método Proposto por Van der Veen, em 1953, por ser aquele que proporcionou a menor carga de ruptura. Essa análise resultou na Figura 16 e em um valor de carga de ruptura de $2.200 \mathrm{kN}$. 


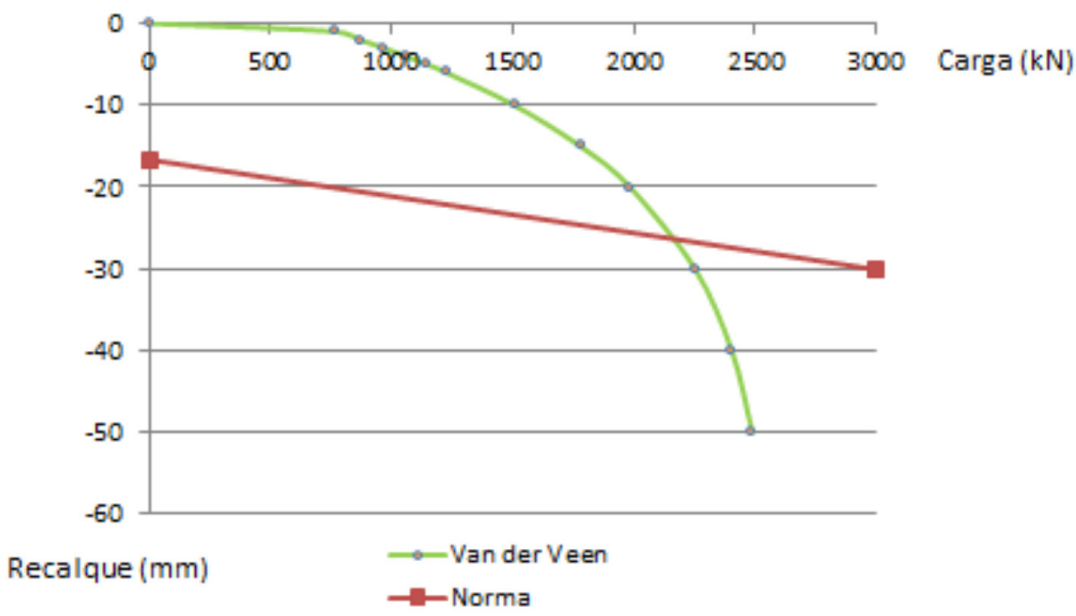

Figura 16 Curva carga versus recalque com Método Convencional NBR 6122:2019.

Fonte: Elaborada pelos autores.

Com base em todos os métodos aplicados e os seus respectivos resultados, foi realizada a análise e comparaçáo dos dados, como apresentado na Tabela 4 a seguir. Observa-se que os valores de carga de ruptura obtidos por meio do Método Van der Veen foi o que mais se aproximou do valor obtido pelo Método Décourt-Quaresma, tendo uma variação de $3,17 \%$ aproximadamente.

\section{TABELA 4}

Dispersão entre os métodos e a previsão de capacidade de carga

\begin{tabular}{|lcccc|}
\hline \multicolumn{1}{c}{ Método } & $\begin{array}{c}\text { Previsão da carga } \\
\text { Ce ruptura pelo } \\
\text { Ćltima(kN) }\end{array}$ & $\begin{array}{c}\text { Método Décourt- } \\
\text {-Quaresma }(1996) \\
(\mathbf{k N})\end{array}$ & Diferença(kN) & Dispersão (\%) \\
\hline Van der Veen (1953) & 2600 & 2685 & -85 & $-3,17$ \\
\hline Chin-Kondner (1970) & 3333 & 2685 & 648 & 24,13 \\
\hline Décourt (1999) & 3693 & 2685 & 1008 & 37,54 \\
\hline NBR 6122:2019 & 2200 & 2685 & 485 & $-18,06$ \\
\hline
\end{tabular}

Fonte: Elaborada pelos autores. 
Destaca-se que, pelo critério de segurança, o menor valor para carga de ruptura obtido foi de $2.200 \mathrm{kN}$ (método convencional - NBR 6122:2019) e, consequentemente, uma carga admissível da estaca teste foi de $1.100 \mathrm{kN}$ com base na prova de carga estática, considerando o fator de segurança igual a 2. Como afirmado anteriormente, a carga admissível em projeto das estacas hélice contínua monitorada de 50 centímetros de diâmetro é de $1.000 \mathrm{kN}$. Pode-se afirmar que esse valor adotado em projeto é inferior ao obtido por meio da análise dos resultados da prova de carga estática e é a favor da segurança.

\section{CONSIDERAÇÓES FINAIS}

Uma obra de fundaçôes em estacas deve ser assegurada não só por um projeto desenvolvido de acordo com ABNT (2019), mas também ter o comportamento e a resistência da sua fundação verificados por meio de ensaios de campo, como a prova de carga estática.

Os resultados obtidos com a prova de carga estática necessitam de uma interpretação adequada, e, quando não se atinge a ruptura no ensaio, esses resultados devem ser extrapolados por métodos adequados. Este trabalho propôs-se a analisar os resultados por meio do método proposto por Chin-Kondner em 1970, Van de Veen em 1953, Décourt em 1999 e o método convencional - NBR 6122:2019. Apesar de serem métodos que não foram propostos para provas de carga estática com carregamento misto, proporcionaram valores que podem ser considerados coerentes, não divergindo mais do que $37,5 \%$ do valor obtido pelo método semiempírico Décourt-Quaresma. Determinou-se que o método proposto por Van Der Veen foi o que resultou em um valor mais próximo do previsto no método semiempírico, apresentando uma variação de 3,2\%.

Pode-se concluir que o valor da carga admissível adotado em projeto de $1.000 \mathrm{kN}$ está a favor da segurança devido à comprovação pela análise da prova de carga estática.

Considera-se que os objetivos do trabalho foram atendidos. Sugere-se para futuras pesquisas: análise de maior quantidade de provas de carga estática com carregamento misto para a constatação do padrão de comportamento desempenhado pelos métodos de extrapolação aplicados neste trabalho; estudo da prova de carga estática deste trabalho com o emprego de outros métodos disponíveis na literatura; formulaçáo de um método de extrapolação de curva carga vs recalque com carregamento misto, por meio de uma amostra maior de provas de carga estática. 


\title{
ALLOWABLE CONTINUOUS FLIGHT AUGER PILE LOAD: COMPARATIVE ANALYSIS BETWEEN STATIC LOADING TEST AND SEMI-EMPIRICAL METHODS
}

\begin{abstract}
This work aims to study methodologies for calculating the allowable pile load based on the results of a static load test provided for in NBR 12131:2006. It is known that, in the design phase, the allowable pile load is found through the use of semi-empirical methods of load capacity forecasting. Field tests can be carried out to guarantee that the pile fulfills its function correctly and to prove the safety factor provided by ABNT (2019), such as the static loading test. This kind of test may lead to pile breaking, with its allowable load determined directly. Otherwise, the extrapolation methods in load-movement records of a static loading test are used to determine this value. With this assumption, this article presents a comparative analysis between allowable load admitted in a project for continuous flight auger pile and the loads found by the application of the Chin-Kondner Extrapolation proposed in 1970, the Brazilian method (NBR 6122:2019), the Van der Veen Method proposed in 1953, and the Décourt Extrapolation proposed in 1999 in the results of static loading test with a mixed load. After the analysis of the results, it was verified that the proximity between the allowable loads was determined through the Van der Veen and Conventional method in relation to that obtained by the DécourtQuaresma load capacity method proposed in 1996.
\end{abstract}

Keywords: Allowable continuous flight auger pile load. Static loading test. Semi-empirical methods to extrapolate load-movement relationship.

\section{REFERÊNCIAS}

ASSOCIAÇÃO BRASILEIRA DE NORMAS TÉCNICAS - ABNT. NBR 6122: Projeto e execução de fundaçóes. 3. ed. Rio de Janeiro: ABNT, 2019.

ASSOCIAÇÃO BRASILEIRA DE NORMAS TÉCNICAS - ABNT. NBR 12131: Estacas: prova de carga estática: Método de ensaio. 2. ed. Rio de Janeiro: ABNT, 2006.

BESSA, A. K. S. et al. Análise de Métodos de Interpretaçáo de Curva Carga x Recalque de Provas de Carga Estática em Fundaçóes Profundas no Nordeste do Brasil. In: CONGRESSO BRASILEIRO DE MECÂNICA DOS SOLOS E ENGENHARIA GEOTÉCNICA, 18., 2016, Belo Horizonte. Anais [...]. Belo Horizonte: ABMS, 2016. Disponível em: https://www.researchgate. net/publication/309223700_Analise_de_Metodos_de_Interpretacao_de_Curva_Carga_x_Re- 
calque_de_Provas_de_Carga_Estatica_em_Fundacoes_Profundas_no_Nordeste_do_Brasil. Acesso em: 27 ago. 2019.

BRSONDA. Relatório de Sondagem - 332.81.806. São Paulo: Brsonda, 2018.

BRANCO, F. O.; ALVES, A. M. de L. Previsão e observaçáo da capacidade de carga de estacas tipo hélice contínua em solo arenoso sedimentar. In: SEMINÁRIO DE ENGENHARIA DE FUNDAÇÓEE ESPECIAIS E GEOTECNIA, 9., São Paulo, 2019. Anais [...]. São Paulo: SEFE, 2019. p. 1-10.

CAMPOS, J. C. de. Elementos de fundaçôes em concreto. São Paulo: Oficina de Textos, 2015.

CINTRA, J. C. A.; AOKI, N. Fundações por estacas: projeto geotécnico. São Paulo: Oficina de Textos, 2010.

CINTRA, J. C. A.; AOKI, N.; ALBIERO, J. H. Fundaçōes diretas: projeto geotécnico. São Paulo: Oficina de Textos, 2011.

CINTRA, J. C. A.; AOKI, N.; TSUHA, C. de H. C.; GIACHETI, H. L Fundaçôes: ensaios estáticos e dinâmicos. São Paulo: Oficina de Textos, 2013.

DÉCOURT, L.; NIYAMA, S. Predicted and Measured Behavior of Displacement Piles in Residual Soils. In: INTERNATIONAL CONFERENCE ON SOIL MECHANICS AND FOUNDATION ENGINEERING, 13., 1994, New Delhi. Proceedings [...]. New Delhi: ICSMFE, 1994. vol. II, p. 477-486.

ESTACA HÉLICE Contínua. Geofix. Disponível em: http://www.geofix.com.br/servico-ehc. php. Acesso em: 10 set. 2021.

FELLENIUS, B. H. Basics of foundation design. British Columbia: 2020. Electronic Edition.

FRANÇA, D. C. de. Provas de carga estáticas instrumentadas em profundidade em estacas escavadas de grande diâmetro (estaçôes). 2011. Dissertação (Mestrado em Engenharia Geotécnica) Universidade de São Paulo, São Paulo, 2011.

MONTEIRO, T. M.; ARAÚJO, C. B. C. de; AGUIAR, M. F. P. de. Análise de métodos semiempíricos nacionais e internacionais para determinação da capacidade de carga axial em estacas tipo raiz. Revista Tecnologia, Fortaleza, n. 2, p. 1-16, dez. 2017. Disponível em: https:// periodicos.unifor.br/tec/article/viewFile/7130/5614. Acesso em: 23 ago. 2019.

TRIO FUNDAÇÓES. Rel. 1971.035. São Paulo: Trio Fundações, 2019.

VELLOSO, D. de A.; LOPES, F. de R. Fundaçōes. São Paulo: Oficina de Textos, 2011.

\section{Contato}

Kamila Rodrigues Cassares Seko

kamila.seko@mackenzie.br

\section{Tramitação}

Recebido em outubro de 2020.

Aprovado em junho de 2021. 